\title{
Ship routing and scheduling: the cart before the horse conjecture
}

\section{Psaraftis, Harilaos N.}

Published in:

Maritime Economics \& Logistics

Link to article, DOI:

10.1057/s41278-017-0080-x

Publication date:

2019

Document Version

Peer reviewed version

Link back to DTU Orbit

Citation (APA):

Psaraftis, H. N. (2019). Ship routing and scheduling: the cart before the horse conjecture. Maritime Economics \& Logistics, 21(1), 111-124. https://doi.org/10.1057/s41278-017-0080-x

\section{General rights}

Copyright and moral rights for the publications made accessible in the public portal are retained by the authors and/or other copyright owners and it is a condition of accessing publications that users recognise and abide by the legal requirements associated with these rights.

- Users may download and print one copy of any publication from the public portal for the purpose of private study or research.

- You may not further distribute the material or use it for any profit-making activity or commercial gain

- You may freely distribute the URL identifying the publication in the public portal

If you believe that this document breaches copyright please contact us providing details, and we will remove access to the work immediately and investigate your claim. 


\title{
Ship routing and scheduling: the cart before the horse conjecture ${ }^{1}$
}

\author{
Harilaos N. Psaraftis \\ Department of Management Engineering \\ Technical University of Denmark
}

19 May 2017

\begin{abstract}
The literature on ship routing and scheduling has grown substantially over the last few decades, with many papers authored by top experts in this area and examining various versions of the problem. Many publication outlets have hosted these papers, with a broad variety of problem formulations, solution approaches and application contexts. Equally broad is the range of angles of these papers, spanning the wide field from mostly theoretical analyses, focusing on specific methodological tools, all the way to applied studies, focusing on specific real-world applications. The basic hypothesis of this paper is that we are increasingly seeing papers that are more of theoretical than practical value, and in fact some of them often place the solution approach before real problem definition. As a result of this approach, the connection between these papers and reality is sometimes distant or elusive. To investigate this hypothesis, this paper tries to explain some misconceptions, refers to a limited sample of such papers, and suggests possible ways to rectify this situation in the future.
\end{abstract}

Keywords: ship routing and scheduling, fleet deployment, speed optimization.

\section{Introduction}

The literature on the routing and scheduling of ships has grown substantially over the last few decades, with many papers examining various versions of the problem and authored by top experts in this area. The area, broadly defined, includes not only ship distribution problems, but also network design, fleet deployment, fleet size and mix, speed optimization, maritime inventory routing, weather routing, offshore logistics, and other related problems. Seminal surveys of such literature include Ronen $(1983,1993)$ and more recently Christiansen et al. (2004, 2013). The latest published survey (Christiansen et al., 2013) lists some 131 papers. Even more impressive is these surveys' citations count: more than 600 Google Scholar citations of the 2004 survey, more than 200 for the 2013 survey. Many publication outlets have hosted these papers, with a broad variety of problem formulations, solution approaches and applications. The 2013 survey lists as many as 62 different outlets for the papers reviewed in the 4 surveys until 2013. Although we do not have more recent statistics, it is likely that this number has further grown since 2013.

\footnotetext{
${ }^{1}$ To appear in Maritime Economics and Logistics.
} 
The above testifies to the growing interest in the area: this is a topic that is very rich in terms of number of people involved, number of papers, and quality of publications. It also has very important implications for industry and maritime policy makers, in the parallel quest of being economically viable and environmentally sustainable.

It is fair to say that the methodological array of these papers has been significant, with methods spanning the entire spectrum of tools of the broader and more general area of transportation science and logistics, and with some tools developed explicitly for maritime logistics problems. Appropriate credit should be given to all those who developed such methodologies.

One of the findings of the 2013 survey was that during earlier years the vast majority of research originated in real-life shipping operations, while more recently one sees more theoretical models that are less grounded in real operations.

In this paper we focus on this last observation, in order to investigate the following hypothesis, which can be formulated in two parts as follows.

\section{$\underline{\text { Hypothesis under investigation }}$}

A. In the ship routing and scheduling area we are increasingly seeing papers that are more of theoretical than practical value.

B. Some of these papers exhibit one or more of the following characteristics:

I. working with instances that are more fictitious than real and/or are unlikely to occur

II. injecting additional and sometimes unnecessary and artificial complexity

III. placing less emphasis on, or even ignoring, real life factors that are important

IV. making assumptions about inputs or functional forms without proper justification

$V$. developing formulations tailored to specific methodological tools rather than the other way around.

Part A of the hypothesis needs no special elaboration. It has been put forward as an observation in Christiansen et al (2013) and we see no reason to challenge it, at least as regards what has happened until 2013. Regarding the period from 2013 on, and looking at the $\mathrm{O}(200)$ papers that cite the above survey, we observe that most are papers published in journals such as European Journal of Operational Research, Transportation Research Parts $B$ and $E$, and Transportation Science, among others, journals that are more likely to focus on methodology than application.

Even though it is difficult to draw conclusions, one can speculate that this trend is linked to the value system that has been established within the publication/faculty promotion-tenure process: if you want to get promoted (and/or get many citations for your work), better publish in journals that are more likely to accept a paper that has a strong methodological content, rather than one that describes an interesting real world application. 
Part $B$ of the hypothesis can be considered as a second-order extension of part $A$, and, as such, merits more analysis. Collectively, issues (I) to (V) in part B can be considered as putting the cart before the horse, hence the subtitle of this paper. By horse we symbolically mean the real-life problem, and by cart the solution approach. Related papers focus on the cart way more than on the horse, and this we believe is starting to become the rule.

There is no reason to doubt that the authors of such papers sincerely intend to publish research that is connected to reality as much as possible, and in fact some of the models that have been developed are actually used by specific shipping companies. At the same time, we also believe that the methodological orientation of the target journals provides a stronger incentive, whose side-effects may be features (I) to (IV) in some cases.

To further investigate part $B$, we do two things in tandem and in parallel: (a) we highlight some issues that we think are important, for which we try to explain some misconceptions, and (b) we go over a rather limited sample of papers in the literature, commenting on them and seeing if some remedies can be applied.

The rest of this paper is structured as follows. The section that follows discusses the issue of time windows in some ship routing and scheduling problems. The next section discusses the issue of speed as a decision variable and the one after that addresses the issue of payload in estimating fuel consumption. Then we comment on the income part of the equation in some problems, and following that we go over some dynamic ship routing and scheduling problems. The penultimate section refers to a problem in liner shipping and the last section presents the paper's conclusions and discusses a possible way forward.

\section{Time windows}

Many ship routing and scheduling papers investigate problems that incorporate time windows into their formulation. See for instance Wang et al. (2014), and Arnesen et al. (2017), among many others. Typically these time windows are expressed as follows:

$\mathrm{T}_{\min } \leq \mathrm{t} \leq \mathrm{T}_{\max }$

where $t$ is the arrival time of the ship at a certain port, and $T_{\min }$ and $T_{\max }$ are lower and upper bounds (respectively) on that arrival time. There may be many such constraints in any given problem formulation, as each may refer to a particular ship-port-cargo combination.

Such constraints seem reasonable at first glance, as they parallel similar constraints in the classical vehicle routing and scheduling literature. However, time windows in a maritime setting are often different from those in an urban setting. The following considerations are important:

Who sets the time windows?

Any formulation such as the above implies that the set of bounds $T_{\min }$ and $T_{\max }$ are exogenous inputs. We recognize that this may be the case in some specific instances, eg a port may be closed during the night, or tides may prevent a ship entering a channel during some times, and so on. However, quite often in a shipping context time windows are not 
exogenous inputs. In the bulk cargo market, should in fact time windows exist at all, they are subject to negotiation and agreement between ship owner and shipper, before the charterparty is signed. It is important to realize that many of these contracts involve the shipment of a single cargo from a certain port $A$ to another port $B$ and there is no routing context with multiple port visits. But even if multiple port visits are involved, a shipping company will not sign a contract in which time windows lead to an infeasible solution, or even to delays which would trigger penalty clauses.

The situation in the liner market is a bit different but essentially it leads to the same conclusion. A shipping line publishes its schedule, which entails specific arrival times for all relevant vessel/port pairs. This does not necessarily imply time windows. If there is a time window agreed to between the shipping line and one of its many customers, it is subject to negotiation and it is set so that feasibility is maintained. If time windows pertain to allowable arrival times at a terminal, there is also a cross-linkage to the traffic of other carriers, and there is negotiation for that too, which is not typically captured in the formulation of the routing and scheduling problem of a single carrier. If a large Maersk EEE ship comes in late, it may probably receive preference over a small feeder ship in terms of berthing (see also point (ii) below).

Some papers go to great lengths on constructing appropriate time windows, mainly as implicit functions of trip length and allowable ship speeds. This is typically done for illustrative problems rather than for real cases. Such a procedure has mainly the effect of limiting the feasible solution space and consequently the overall computational effort. Specific solution techniques that are used in solving these problems (for instance, column generation, dynamic programming, various neighborhood search methods, or others) may require excessive running times or may break down computationally in case time windows do not exist or are very loose. So time windows come in handy if one wants to avoid such issues. At times time windows give the impression of being introduced less because they are part of the real world problem and more so that specific solution tools can be applied.

Are time windows hard constraints?

A more realistic and flexible scenario is that time windows are considered as soft constraints, that is, can be violated, possibly at a penalty. Waiting if the ship arrives early may or may not entail a cost. If a ship arrives late, the solution is not infeasible but may entail a delay cost, or a penalty. Penalties are typically functions of ship type and size. Some papers actually assume soft time windows (see for instance Fagerholt (2001) among others). But even then, the issues raised in the previous paragraph are still valid. Even a soft time window is subject to negotiation and agreement between the two contracting parties.

All of the above mean that many times setting time windows is an integral part of the overall decision process in the ship routing and scheduling problem. As such, time windows often are not exogenous inputs, as is usually the case in an urban transport setting. In a maritime setting it is likely that these time windows are either superfluous, or they are such that specific solutions are obtained or the feasible solution space is appropriately limited. In many cases, they dictate the solution itself and are decided upon so that this solution is feasible. 
If this is so, how should time windows be embedded into these problems? The following iterative procedure is a suggestion.

STEP 1 . The problem is first solved without time windows, and the shipping company gives the shipper an indication of when the ship can arrive at the port to pick up or deliver the cargoes.

STEP 2. Once the no-window problem is solved, if the pickup or delivery times are acceptable to the shipper, there is no need to do anything else, other than perhaps enter these times into the contract, maybe with appropriate penalty clauses if these times are not met.

STEP 3 . If the times are not agreeable to the shipper, the shipper suggests some alternative time windows, hopefully not very remote from the shipping company's suggestion, and the problem is solved again with these time windows.

STEP 4 . The process is repeated until a mutually agreeable solution is found.

It is always conceivable that this process may not terminate with a feasible solution, at least between a given pair of shipping company and shipper. But it is unlikely that at the end of this process no solution whatsoever is found. Shipbrokers are very good in this matchmaking process. But to our knowledge, their role in a ship routing and scheduling context is practically non-existent.

As things stand, a possible deficiency of the proposed approach is that it may break down in STEP 1. Solving the problem without time windows may render certain methodological tools inefficient or even inappropriate. But this should not be a reason for instituting time windows in the first place.

\section{Non inclusion of speed as a decision variable}

Most of the earlier models found in the ship routing and scheduling literature assume fixed and known speeds for the ships, and tailor their solution approaches accordingly. See for instance Rana and Vickson (1991), Agarwal and Ergun (2008), Hwang et al (2008), and Grønhaug et al (2010), among others. In fact speed has been typically considered as an implicit input to the problem, in the sense that it has been used to compute various other explicit inputs that depend on speed, such as inter-port sailing times and fuel costs.

Assuming a fixed speed and not including speed as a decision variable ignores the fact that ships do not trade at predetermined speeds. Also, this may in some cases remove flexibility in the overall decision making process and render fixed-speed solutions sub-optimal. For instance, a ship sailing at a prescribed speed to a certain port, only to have to wait there because the port is congested, may be a higher cost solution than one in which the ship is allowed to sail at a lower speed so as to arrive when a berth is available. Overall emissions would be higher in that case as well. There are several models in the literature that include port capacity constraints, berth occupancy constraints, time window constraints or other constraints that preclude the simultaneous service of more than a given number of vessels. Such situations would conceivably be easier to handle were it not for the assumed constancy in ship speed. Schedule disruption in liner shipping would also typically require flexibility on ship speed in order to recoup lost time and one would in fact consider such flexibility as one of the most important tools to handle a disrupted schedule (see, for instance, Li et al., 2015). 
Yet, this author has handled at least one paper on disruption management in which ship speed was considered fixed and constant (incidentally, that paper was rejected).

Obviously, if speed is not included as a decision variable the solution approach is different from, and quite likely much simpler than if the opposite is the case. Traditional "vehicle routing problem" (VRP) solution methods can be adapted more easily to a maritime setting if ship speed is assumed fixed. And even though there might be valid reasons for considering speed a fixed input (for instance, contractual obligations), in general if speed is not allowed to vary some flexibility will be lost and solutions may be inferior.

We acknowledge that recently, and after the speed model taxonomy of Psaraftis and Kontovas (2013), more papers incorporating speed as a decision variable have been published. A recent example is a paper by Xia et al. (2015), which addresses a joint fleet deployment, speed optimization and cargo allocation problem in liner shipping. Interestingly enough, this paper considers fuel consumption not only a function of ship speed, but also of ship payload, which is related to the section that follows.

\section{No payload considerations in fuel consumption function}

Generally in any scenario in which ship payload varies along the route, such as in pickup and delivery situations, adequate provision should be taken so that the fuel consumption function, other than being a function of speed, is also a function of ship payload. Pickup and delivery means that a ship picks up distinct cargoes from distinct ports and delivers them to other distinct ports. In this case the load profile of the ship may vary along the route. Note however that, to our knowledge, most related papers in the literature assume a fuel consumption function that is independent of ship payload. See, for instance, Fagerholt (2001), Norstad et al. (2011), and Fagerholt and Ronen (2013). This may misrepresent fuel costs along the route and hence may lead to suboptimal solutions.

In fact, the assumption in many papers that no dependency between fuel consumption and ship payload is considered can cause serious under- or over-estimation of fuel costs. This is so because ship resistance and hence fuel consumption at a given speed can be drastically different if the ship is full, in ballast or at an intermediate loading condition. The difference can be as high as $40 \%$ or even higher, depending on ship type. In tankers and bulk carriers we usually have a "binary" situation as the ship is typically either full or in ballast, and the difference in fuel consumption between these two extreme conditions can be quite substantial. In container vessels the ship is typically intermediately laden, but ships in some trunk routes are mostly full in one direction and mostly empty in the opposite. This is close to a binary situation and one would expect non-trivial differences in fuel consumption as well.

Similar considerations pertain to all ship types. In general, if a ship's loading condition varies along the legs of a ship's route (which is typical in pickup and delivery scenarios in which the ship is not fully laden all the time), it is important that the dependency between ship load and fuel consumption along that route be realistically modeled. It would not make sense to obtain solutions that are claimed to be within, say, 1,2 or $5 \%$ from the "optimum", or even at the exact "optimum", if the fuel consumption function is misrepresented by 10,20 or $40 \%$. And even though it is conceivable that routing decisions may not change if dependency on 
payload is not taken into account, this is not always the case, as shown in Psaraftis and Kontovas (2014).

So another gap between model and reality that is seen in quite a large portion of the ship routing and scheduling literature is the above omission. According to the updated survey of speed models by Psaraftis and Kontovas (2016), of the approximately 50 papers surveyed (not all under the ship routing and scheduling umbrella) only 8 consider a dependency on payload, and of the 24 ship routing an scheduling papers in that survey, only 3 do. Of course considering such dependency may render some of the solution approaches for these problems difficult or even impossible to apply, so these are again cases where using specific methodological tools may take precedence over formulation realism.

\section{Ignoring the income part of the equation}

Another modeling assumption that is reflected in most ship routing and scheduling problems is that these models do not include the state of the market (spot rate, or other freight rate) as part of their formulation. See for instance, Brown et al. (1987), Bausch et al. (1998), and Meng and Wang (2011) among others. In these papers, the income component of the problem is typically assumed fixed, and the typical objective is to minimize cost. However, it is well known in shipping that an important tradeoff, in pursuit of higher profits for a ship owner, is the balance between more trips and hence more income at a higher speed, and less trips because of high fuel cost. This is so when the ship is on spot charter, in which case the fuel is paid for by the ship owner. While on spot charter, the owner would like to take advantage of high freight rates by hauling as much cargo as possible within a given period of time. Conversely, if the market is low, ships tend to reduce speed, as the additional revenue from hauling more cargo is less than the additional cost of the fuel. A main reason for slow steaming in recent years is the depressed state of the market (the fact that fuel prices have also dropped has masked the extent of this phenomenon).

It is not often realized that such behavior is also relevant for the charterer, if the ship is on time or bareboat charter. The objective of the charterer is to minimize costs, including fuel costs, which are paid by the charterer for these types of contract. If the market is high, the charterer may want to speed up so as to pay less for time chartering the ship, or even conceivably charter out extra capacity. Whether owner or charterer, not factoring in the state of the market means that the model will not be able to capture one of the fundamental facets of shipping industry behavior, according to which the state of the market, along with the price of fuel, are the two main determinants of the speed of vessels.

Given that ship speeds are anything but predetermined, those who pay for the fuel, that is, the ship owner if the ship is on spot charter, or the charterer if the ship is on time or bareboat charter, will typically choose a speed that optimizes their objective, be that profit in the case of a ship owner, or cost in the case of the charterer. As shown in Devanney (2010), in case costs or profits are expressed on an average per day basis, and even though the two optimization problems (that of the ship owner and that of the charterer) may seem at first glance different, in fact they turn out to be mathematically the same. The same is true for the corresponding optimal speeds. The assumption of course is that speed is allowed to be chosen freely and is not fixed or otherwise constrained, either explicitly or implicitly, by contractual agreement. 
Consider now the following rudimentary scenario, which actually involves no routing decision. A containership of capacity Q (TEU) shuttles between port A and port B, whose interport distance is $L$ (nautical miles-nm). The ship's speed is $v$ (nm/day) which is within the bracket $V_{\min }$ and $V_{\max }$. The upper bound on ship speed is implied by the ship's maximum horsepower, and the lower bound on that speed is a function of engine technology, as (contrary to a car engine) a ship engine will stall below a certain speed. Assume the ship is full in both directions and that the freight rate received by the ship owner is $R(\$ / T E U)$. Assume that the fuel price is $p\left(\$ /\right.$ ton) and that the fuel consumption function is $F C=k v^{3}$ (tons/day) with $\mathrm{k}$ being a constant. Assume finally that miscellaneous other operating expenses are $\mathrm{X}\left(\$ /\right.$ day) and that port turnaround times are ignored. $Q, L, R, p, k, V_{\min }, V_{\max }$ and $\mathrm{X}$ are assumed known inputs and the sole decision variable is $\mathrm{V}$.

In this scenario, we can compute various attributes of the round trip, such as

Round trip time $\mathrm{T}=2 \mathrm{~L} / \mathrm{v}$ (days)

Cost per round trip $C=T\left(p k v^{3}+X\right)=2\left(p k L v^{2}+L X / v\right)(\$)$

Income per round trip I $=2 R Q(\$)$

Profit per round trip $\mathrm{P}=\mathrm{I}-\mathrm{C}=2\left(\mathrm{RQ}-\mathrm{pkLv} \mathrm{v}^{2}-\mathrm{LX} / \mathrm{v}\right)(\$)$

Profit per unit time $\mathrm{P}^{\prime}=\mathrm{P} / \mathrm{T}=\mathrm{RQv} / \mathrm{L}-\mathrm{pkv}^{3}-\mathrm{X}(\$ /$ day $)$

The optimal ship speed depends on what is the objective to be optimized.

If the objective is to minimize $C$, the optimal speed is

$\mathrm{V}^{*}=\mathrm{V}_{\min }$ if $\mathrm{V}_{\min }>\mathrm{V}_{0}$

$\mathrm{V}^{*}=\mathrm{V}_{0}$ if $\mathrm{V}_{\min } \leq \mathrm{V}_{0} \leq \mathrm{V}_{\max }$

$\mathrm{V}^{*}=\mathrm{V}_{\max }$ if $\mathrm{V}_{\max }<\mathrm{V}_{0}$

with $\mathrm{V}_{0}=(\mathrm{X} / 2 \mathrm{pk})^{1 / 3}$

Interestingly enough, the optimal speed is the same if the objective is to maximize $\mathrm{P}$. This is so because the round trip income I is constant and equal to $2 R Q$, independent of ship speed. In that sense, if this is the objective, the freight rate $R$ (or, the state of the market) has no influence on optimal ship speed. This is contrary to how the market behaves: higher speeds are induced by higher values of $R$ and vice versa, and the above objectives failed to capture the influence of $R$.

The reason such a formulation is deficient is because it does not take into account the possible additional income due to more trips if ship speed goes up. A formulation that takes care of such deficiency is to maximize profit per unit time, that is, $\mathrm{P}$ '.

If we do this, the solution is

$\mathrm{V}^{\star *}=\mathrm{V}_{\min }$ if $\mathrm{V}_{\min }>\mathrm{V}_{00}$

$\mathrm{V}^{* *}=\mathrm{V}_{00}$ if $\mathrm{V}_{\min } \leq \mathrm{V}_{1} \leq \mathrm{V}_{\max }$

$\mathrm{V}^{* *}=\mathrm{V}_{\max }$ if $\mathrm{V}_{\max }<\mathrm{V}_{00}$

with $v_{00}=(R Q / 3 p k L)^{1 / 2}$

This result is not new. See for instance Ronen (1982) and more recently Magirou et al. (2015) for similar results. None of these results however pertain to a ship routing and scheduling context. One can see that, barring speed hitting its upper or lower bounds, in the 
above formulation optimal speed is indeed freight-rate dependent, as much as it is fuel price dependent. Higher freight rates (and/or lower fuel prices) induce higher speeds and vice versa, which is exactly how the market behaves.

If the above is true for such a simple scenario, it is equally true for more complex scenarios, involving route selection, fleet deployment, and other scenarios. To our knowledge, the majority of papers in the ship routing and scheduling literature consider cost (in the majority of cases) or profit (less frequently) on a per trip or per set of routes basis and not on a per unit time basis. As shown above, the difference in objective function can be important. If the income part of the equation is a constant, these approaches cannot capture the possible effect of the freight rate on ship speed. Of course, an objective function that is defined as the ratio of route cost (or profit) divided by the corresponding route duration is non-linear both in the numerator and in the denominator (and obviously in itself) and we have not seen it in a ship routing and scheduling context. This could be worth exploring further, however it would likely entail different solution techniques from those traditionally used.

\section{Dynamic ship routing and scheduling}

The literature on dynamic ship routing and scheduling problems is still, in many respects, rather scant, even though the corresponding literature on dynamic VRPs is impressive (see for instance Psaraftis et al. (2016) for a recent survey). By dynamic here we mean that inputs such as specific cargo requests appear concurrently with the execution of the ship's route.

Still, there have been a number of recent papers that consider a dynamic setting, that is, a ship that can alter its course to serve cargoes that appear in real time. See for instance Tirado and Hvattum (2016), among others. This paper assumes a stochastic and dynamic setting for a set of ships that operate in a way similar to a dial-a-ride service, that is, are available to pick up and deliver cargoes that appear in a dynamic fashion. Local search heuristics are used to construct the ship routes, and solutions very close to the optimum are generated.

Interesting as this approach might be, operating ships that have at any point in time enough idle capacity to be able to accommodate cargoes that appear in real time is a scenario very unlikely to be encountered in any major commercial shipping market (drybulk, oil, chemical or unitized). Even though the above paper refers to industrial shipping, the specific commercial context in which these scenarios can be encountered in real life is not described, and all of its test runs are hypothetical. There is nothing a priori wrong with this, however an industrial shipping company typically uses full shiploads to carry its own cargoes, as it would make little sense to use larger ships for smaller cargoes and hope that at some point during the execution of the route some other cargoes will appear to fill out the ship's spare capacity. The same is the case for spot cargoes. If a spot cargo of (say) 20,000 tons appears, it would make little sense to charter a 50,000 ton capacity ship, hoping that along that ship's route additional cargoes will become available to use the spare ship capacity. So even if a realistic scenario is conceivably defined, the risk of serious financial losses due to low ship utilization in a dynamic scenario is very real. Interestingly enough however, even though the above paper purports to solve a stochastic problem, such a risk is not part of its formulation. 
It should be acknowledged that such a scenario could very well be relevant in a maritime urban transportation setting (eg, a maritime dial-a-ride system in Venice or in Amsterdam). But we are not aware of such applications in the existing literature.

\section{Role of demand functions in liner problems}

The literature on liner (and specifically containership) routing and scheduling problems is rich and growing, and it also encompasses network design, fleet deployment, fleet size and mix, and other related problems - see for instance the recent survey of Meng et al (2014) and the recent book of Lee and Meng (2015). Here we refer to a paper by Wang et al. (2013). The authors examine the optimal containership schedule with transit-time-sensitive demand which is assumed to be a decreasing continuous function of transit time. A mixed-integer nonlinear non-convex optimization model is formulated to maximize the total profit of a ship route. In view of the problem structure, a branch-and-bound based holistic solution method is developed. It is demonstrated that this solution method can obtain an $\varepsilon$-optimal solution in a finite number of iterations for general forms of transit-time-sensitive demand.

Much of the paper's effort is spent on theory and methodology, on how the problem is solved, on how $\varepsilon$-optimality can be proven, and on other methodological issues. The approach is interesting and technically sound, however a critical modeling assumption is that container demand $D_{i j}$ between any given ports $i$ and $j$ is a known and decreasing function of the transit time tij between these two ports. This means that if that transit time goes up due to (for instance) reduced ship speed or cargo being transshipped via an intermediate port, then less cargo would like to go from $i$ to $j$. Then some effort is spent to examine test cases with various hypothetical forms of that function and how the solution might change for each of these forms.

Ordinarily, one would imagine that the hypothesis that demand between two ports is a function of transit time, and actually a decreasing function, would be tested against evidence, and such testing would be part of the analysis of the paper, or would be proven somewhere else. However, neither of the above is the case, the paper simply stating the hypothesis as an assumption and then proceeding with the rest of the analysis. This means that the above hypothesis is not justified. One could actually argue that other factors, such as the freight rate the line charges from $i$ to $j$, or the frequency of service, or other service attributes, or finally some macroeconomic factors, could be even more important factors for determining demand. However, such factors are not considered. Yet, these factors could be critical in both the formulation of the problem and in the solution methods that are used. They could also be critical in making the effort more relevant in solving a realistic problem than a mainly theoretical contribution.

\section{Conclusions and recommendations}

Several additional examples could be mentioned but were not included due to size limitations. As the exposition of the previous sections is non-encyclopedic, no concrete generalizations from it can be drawn. What may be a trend is only a clue at this point in time. 
But on the basis of the previous sections, we personally believe that the clue cannot be ignored.

The class of ship routing and scheduling problems was chosen to test the hypothesis of this paper, and this does not mean that this is the only class of problems in which such a hypothesis can be tested. A colleague who has been Editor-In-Chief of a top transportation journal has characterized many papers submitted to the journal as practising "recreational mathematics". Papers with complex notation, complex formulations and complex solution approaches whose connection with reality is sometimes elusive can be tagged this label.

For many authors, and this author claims no special exception, publishing a paper in a good journal is more interesting, or in fact may only be possible, if the paper focuses more on theory and methodology rather than application. In the quest for publishing such papers, their degree of realism often comes lower in priority, both for the authors and for those engaged in the review process. We believe that these papers do represent a trend in the literature, and this is mostly based on the fact that they are written by colleagues who can be considered as trend-setters in the area. Once a specific trend is established, it may in turn encourage the production of more papers that conform to this trend and discourage other works that are important but can be considered outliers only because they do not fit the trend. This is not desirable in our opinion.

We believe that the nature of the reviewing process in related journals is such that papers of this nature are routinely encouraged: a referee is unlikely to recommend acceptance if there is no strong methodological component. This is fair enough. However, it is also unlikely for a referee to recommend rejection or major revision if the application is not realistic, if some important factors are left out of the formulation, or finally if some assumptions or data are not justified. We believe that this needs to be corrected.

In our opinion, the recommendation voiced in the latest survey of Christiansen et al. (2013) to assemble a set of benchmark data instances similar to those available in land transportation would certainly make sense. However, this is not an easy task and a fundamental proviso is that these instances should be realistic. Another recommendation is to include in the set of referees at least one person who comes from a shipping company, or from a port or terminal if the paper deals with the latter. However, this can be easier said than done. A referee with real-world background may not easily understand algorithms, mathematical programming and other tools. Still, his or her contribution may be important.

If the scientific community is to be more useful to the shipping industry in the future, this author feels that a rechanneling of efforts is warranted, more to the modeling/formulation phase and less to the methodological phase of an optimization problem. If the trend continues, whatever trust the shipping industry has in academic research (already not very high in our opinion) would be increasingly difficult to maintain. A good model need not be complex. Adding unnecessary and sometimes artificial complexity should be avoided. A good method that solves a problem unlikely to occur in practice is of limited utility. A problem that is defined so that a specific tool can be used is not so useful either. 
Needless to say, it will be the individual and collective stance of authors, referees, editors and all involved in the paper review process that will ultimately determine whether or not the above recommendations stand a reasonable chance to be acted upon in the future.

\section{Acknowledgments}

I would like to thank the Editor and two anonymous referees for their comments.

\section{References}

Agarwal, R. and Ö. Ergun, 2008, Ship Scheduling and Network Design for Cargo routing in Liner Shipping, Transportation Science 42, 2, 175-196.

Bausch, D., Brown, G. and Ronen, D.,1998. Scheduling short-term marine transport of bulk products. Maritime Policy and Management 25, 335-348.

Brown, G., Graves, G. and Ronen, D., 1987. Scheduling ocean transportation of crude oil. Management Science 33, 335-346.

Christiansen, M., Fagerholt, K., Ronen, D., 2004. Ship routing and scheduling: status and perspectives. Transportation Science 38 (1), 1-18.

Christiansen, M., Fagerholt, K., Nygreen, B., Ronen, D., 2013, Ship routing and scheduling in the new millennium, European Journal of Operational Research 228, 467-483.

Devanney, J.W., 2010. The Impact of Bunker Price on VLCC Spot Rates. Proc. Of the 3rd International Symposium on Ship Operations, Management and Economics, SNAME Greek Section, Athens, Greece, October.

Grønhaug, R., M. Christiansen, G. Desaulniers, and J. Desrosiers, 2010, A Branch-andPrice Method for a Liquefied Natural Gas Inventory Routing Problem, Transportation Science, Vol. 44, No. 3, 400-415.

Fagerholt, K., 2001, Ship scheduling with soft time windows: an optimization based approach, European Journal of Operational Research 131, 559-571.

Fagerholt, K. and D. Ronen, 2013, Bulk ship routing and scheduling: solving practical problems may provide better results, Maritime Policy and Management, 40 (1), 48-64.

Hwang, H.-S., S. Visoldilokpun, and J.M. Rosenberger, 2008, A Branch-and-Price-and-Cut Method for Ship Scheduling with Limited Risk, Transportation Science, Vol. 42, No. 3, 336351.

Lee, C.Y. and Meng, Q (eds.) 2015. Handbook of Ocean Container Transportation Logistics: Making Global Supply Chains Effective, Springer.

Li, C., Qi, X., and Lee, C.Y., 2015, Disruption recovery for a vessel in liner Shipping, 
Transportation Science, Vol. 49, No. 4, 900-921.

Magirou, E.F., Psaraftis, H-N., and Bouritas, T., 2015, The economic speed of an oceangoing vessel in a dynamic setting. Transportation Research Part B 76, 48-67.

Meng, Q. and Wang S., 2011. Optimal operating strategy for a long-haul liner service route. European Journal of Operational Research 215, 105-114.

Meng, Q., Wang, S., Andersson, H., and Thun, K., 2014, Containership Routing and Scheduling in Liner Shipping: Overview and Future Research Directions, Transportation Science 48 (2):265-280.

Norstad, I, Fagerholt,K. and Laporte, G., 2011, Tramp ship routing and scheduling with speed optimization. Transportation Research Part C, 19, 853-865.

Psaraftis, H.N., Kontovas, C.A., 2013, Speed Models for Energy-Efficient Maritime Transportation: a Taxomomy and Survey. Transportation Research Part C, 26, 331-351.

Psaraftis, H. N., and Kontovas, C. A. 2014. Ship speed optimization: Concepts, models and combined speed-routing scenarios. Transportation Research Part C, 44, 52-69.

Psaraftis, H. N., C.A. Kontovas, 2016, Green maritime transportation: Speed and route optimization, chapter in Green Transportation Logistics: in Search for Win-Win Solutions, H.N. Psaraftis (ed.) Springer.

Psaraftis, H.N., M. Wen and C.A. Kontovas, 2016, Dynamic Vehicle Routing: Three Decades and Counting, Networks Vol. 67, issue 1, 3-31, DOI 10.1002/net. 21628.

Rana, K., and R.G. Vickson, 1991, "Routing Container Ships Using Lagrangean Relaxation and Decomposition," Transportation Science, Vol. 25, No. 3, 201-214.

Ronen D., 1982. The Effect of Oil Price on the Optimal Speed of Ships. Journal of the Operational Research Society, 33, 1035-1040.

Ronen, D., 1983, Cargo ships routing and scheduling: survey of models and problems. European Journal of Operational Research 12, 119-126.

Ronen, D., 1993, Ships scheduling: the last decade. European Journal of Operational Research 71 (3), 325-333.

Stopford M., 2008, Maritime Economics, $3^{\text {rd }}$ Edition, Taylor \& Francis, London.

Tirado, G., Hvattum, L. M. 2016, Improved solutions to dynamic and stochastic maritime pick-up and delivery problems using local search, Annals of Operations Research, DOI 10.1007/s10479-016-2177-5. 
Wang, S., Meng, Q. Liu, Z., 2013, Containership scheduling with transit-time-sensitive container shipment demand, Transportation Research Part B, 54 (2013) 68-83.

Wang, S., Alharbi, A., Davy, P., 2014, Liner ship route schedule design with port time windows, Transportation Research Part C 41, 1-17.

Xia, J., Li, K.X., Ma, H., Xu, Z. (2015) Joint Planning of Fleet Deployment, Speed Optimization, and Cargo Allocation for Liner Shipping. Transportation Science 49(4):922 938. 